\title{
Desigualdades en América Latina. Registros sociológicos de un problema urgente. Reseña de Benza, G. y Kessler, G.. (2020). La inueva? estructura social de América Latina. Cambios y persistencias después de la ola de gobiernos progresistas. Buenos Aires: Siglo XXI Editores.
}

\author{
Hernán Caneva \\ hernancaneva@gmail.com \\ Centro Interdisciplinario de Metodología de \\ las Ciencias Sociales. Instituto de \\ Investigaciones en Humanidades y Ciencias \\ Sociales (IdIHCS - CONICET). Universidad \\ Nacional de La Plata, Argentina
}

Recepción: 15 Mayo 2020

Aprobación: 17 Octubre 2020

Publicación: 01 Febrero 2021

Cita sugerida: Caneva, H. (2021). Desigualdades en América

Latina. Registros sociológicos de un problema urgente [Revisión del libro La ¿nueva? estructura social de América Latina.

Cambios y persistencias después de la ola de gobiernos

progresistas de G. Benza y G. Kessler. Cuestiones de Sociología,

24, e121. https://doi.org/10.24215/23468904e121

\section{Introducción}

Nos encontramos en tiempos de profunda incertidumbre social, política y económica, y en el marco de una crisis sanitaria que repercute sobre la configuración del modelo de acumulación capitalista a nivel global a causa de la pandemia Co-vid 19. Para quienes formamos parte de las ciencias sociales, conocer, comprender y transformar la estructura social de nuestra América se convierte en un desafío intelectual y a la vez político, habida cuenta de las desigualdades que persisten y se reproducen en toda la región. 
Pero el desafío involucra también a la política y a la ciudadanía en general. Así, la situación sanitaria que nos tocó atravesar en el año 2020 agudiza conflictos que provienen de un "ciclo" político-económico previo y que desde el año 2015 ha estado marcado por políticas regresivas, que -con sus matices entre países y regiones- ha repercutido en la profundización de exclusiones y desigualdades persistentes en materia de ingresos, salud, educación y vivienda, entre otras. Los problemas estructurales de la región, sin embargo, dan cuenta de una historia todavía más larga.

El libro de Gabriela Benza y Gabriel Kessler, titulado La ¿nueva? estructura social de América Latina. Cambios y persistencias después de la ola de gobiernos progresistas (2020) viene a publicarse en una coyuntura más que oportuna, al menos por dos razones: la primera, porque nos ofrece una mirada comparativa entre países y regiones, tomando como referencia algunas variables centrales de la estructura social del período reciente. La segunda, y ligada a la anterior, porque nos propone un conjunto de hipótesis e interrogantes de gran relevancia para pensar "qué hacer" en el contexto actual, y particularmente para reflexionar sobre qué se podría hacer desde las políticas públicas para enfrentar los problemas de agenda.

Esta reseña se plantea como una mirada "situada", que nos permita recuperar algunas ideas que considero relevantes para aportar a la discusión sobre el problema urgente de la desigualdad en la región. Para comenzar, pienso que habría que poner en claro qué entendemos por desigualdad/es; es decir, cuáles son los criterios que nos permiten definirla y señalar su singularidad frente a otros problemas como la exclusión social o la pobreza. En este sentido, para definir los contornos semánticos de la noción de desigualdad y, sobre todo, para justificar su relevancia sociológica y política, podríamos problematizar cuál es su alcance ético y normativo en el marco de nuestra cultura, la cual está profundamente atravesada por ideales de libertad individual. Entonces, deberíamos considerar cuáles son los sentidos implicados en la concepción de libertad individual, cuáles son los alcances y limitaciones de la emancipación humana y cómo estos ideales se tensionan con la concepción de igualdad que gobierna a una significativa parte del sentido común. Mi argumento es que la reflexión ético-política sobre la tensión libertad-igualdad tiene una significativa relación con la definición de la desigualdad y las acciones sociales y políticas en su abordaje. Darnos esta discusión nos permite analizar críticamente cuáles han sido y cuáles son las características de las políticas que se han venido desarrollando en las últimas décadas en la región en materia de desigualdad.

En este sentido, considero que el libro de Benza y Kessler realiza un aporte sustancial al debate social y político actual sobre los cambios y continuidades en la estructura social de los países de nuestra región, al poner en escena la multidimensionalidad y complejidad contenida en el problema de la desigualdad. El texto parte de preguntarse "¿cómo es la estructura social de América Latina en la actualidad?", y en su abordaje revela problemas aporéticos que se analizan con destacado rigor teórico-metodológico.

A las/los lectores, les sugiero recorrer el libro atendiendo a las preguntas y afirmaciones que los autores plantean en la Introducción. Para abordar tan complejo interrogante, cómo es la estructura social de América Latina en la actualidad, los autores proponen miradas que nos aproximan a los procesos 
socio-económicos, socio-culturales y socio-políticos que atravesaron la región desde mediados del siglo $\mathrm{XX}$, sosteniendo que transformaron sensiblemente las bases de la estructura social y, con ella, algunas asimetrías y desigualdades sedimentadas durante siglos. Esa mirada temporal de amplio espectro, asimismo, nos ayuda a ubicarnos en la temporalidad del período neoliberal, que podríamos situar a finales de los años 1970, pero que se consolidó fundamentalmente en la década de 1990. Esas dos temporalidades, la de amplio espectro y la del período neoliberal, nos permiten -en línea con los autores- comprender cuáles han sido las tendencias hacia la reducción o ampliación de las desigualdades en la región durante las últimas dos décadas.

Así, a modo de espejo con el período neoliberal, los autores piensan los cambios y continuidades que se dieron durante los años de los llamados "gobiernos postneoliberales", entre 1998 y 2015, que, con sus diferentes características según cada país, desarrollaron políticas sociales inclusivas y/o progresistas en la región. Esta lectura "en espejo" les permite pensar históricamente el problema de las desigualdades, y al mismo tiempo, relevar algunos indicadores para interrogar en qué medida durante el ciclo de gobiernos progresistas hubo una reducción de aquellas.

En esta dirección, los autores plantean que durante los años 90 la agenda de los gobiernos neoliberales avanzó en el tratamiento de problemas ligados a la exclusión y a la pobreza, fundamentalmente en materia de salud y educación, y que los gobiernos del ciclo "post-neoliberal" avanzaron muy marcadamente en el cumplimiento de esa agenda, pero no tan sostenidamente en el problema de la desigualdad.

En línea con los autores, podemos pensar que la agenda de la desigualdad es mucho más amplia que la de la pobreza, porque no se reduce a enfrentar el problema de la exclusión de los sectores más postergados o a brindar asistencias que incrementen su consumo. El problema de la desigualdad exige pensar y abordar de forma conjunta la dimensión del ingreso, el trabajo, la vivienda, la salud, la educación, los grupos étnicos, el género y la clase. Por ello, los diagnósticos que podemos realizar con respecto a este problema en la región exigen una mirada que diferencie entre países, entre regiones y al interior de cada estructura social, más allá de las tendencias generales al mejoramiento de algunos indicadores, como la esperanza de vida al nacer o el progresivo acceso a la educación.

En este sentido, y a partir de la recuperación de diferentes fuentes, los autores sostienen que ha habido una existente, aunque deficitaria, reducción de las desigualdades en la región durante los últimos 15 a 20 años. Por esta razón, nos invitan a mirar en profundidad y de manera comparada los principales indicadores que ilustran el problema de la desigualdad en su multidimensionalidad y complejidad: demografía, familia, ingresos, educación, salud y vivienda.

Cabe señalar que cada capítulo del libro realiza un aporte específico al desarrollo de estos aspectos, planteando cuáles han sido los avances y retrocesos, así como las principales discusiones de agenda pública actual. En este sentido, una sugerencia para las/los lectores es que al recorrer cada capítulo tengan en cuenta que se plantea una mirada comparada entre países y al interior de los países. Para no extraviarnos entre guarismos, y atentos al desafío que 
conlleva comparar semejante volumen de datos referentes de cada aspecto de la desigualdad, los autores realizan síntesis muy bien condensadas al finalizar cada sección del libro. Otra recomendación para las/los lectores que se encuentren realizando investigaciones en alguna de estas áreas o aspectos de la estructura social y de la desigualdad es que el libro posibilita leer cada capítulo como una unidad relativamente autónoma, por lo que podrán detenerse en cada campo de problemas y de discusiones, así como retomar datos comparativos que puedan serles de utilidad.

En esta reseña, me parece pertinente centrarme en las Conclusiones de la obra, y retomar algunas ideas que aporten a la reflexión y al debate sobre el problema de la desigualdad en la región. En ellas los autores se preguntan (y nos interpelan a preguntarnos) cómo es hoy la estructura social de América Latina comparada con la del pasado. Es decir, se preguntan cómo mutó la estructura social en las últimas décadas y en el nuevo milenio. En esta dirección, realizan una suerte de "balance" considerando las variables clave para analizar cómo es la estructura social en esta región (demografía, familia, ingresos, educación, salud y vivienda).

La primera consideración en relación con estos interrogantes es que debemos tener en cuenta algunas tendencias de largo plazo; es decir, transformaciones sustanciales en las características de la vida de la población de nuestra América, las cuales se desarrollaron desde mediados del siglo XX. Si comparamos algunas variables o indicadores que se remontan a 1950 con los de la actualidad, podremos notar que se produjeron mejoramientos ostensibles en el nivel de vida de las poblaciones de la región en general. Por ejemplo, la esperanza de vida al nacer, que pasó de 51 años en 1950 a 75 años en 2015; la tasa de fecundidad, que se redujo en tres veces a lo largo del período, lo que no necesariamente indica un mejoramiento en el nivel de vida, pero sí da cuenta de una mayor regulación de la tasa de natalidad. En el mismo sentido, se produjeron otros cambios sociales que muestran una disminución de las desigualdades en el marco de esta temporalidad de largo plazo, como la progresiva incorporación de las mujeres en el mercado de trabajo y la ampliación de la cobertura en educación, salud, vivienda y servicios, que si bien plantea la discusión acerca de la calidad, da cuenta de la inclusión de sectores postergados.

Ahora bien, como sostienen los autores, si las tendencias de largo plazo ilustran significativos y progresivos cambios en toda la región, las tendencias de mediano plazo, esto es, las que podemos ubicar desde finales del siglo XX hasta 2015, período atravesado por el post-neoliberalismo, exigen una mirada mucho más aguda para establecer cuáles han sido los avances y retrocesos en la reducción de las desigualdades.

Los diferentes datos que se exponen en el libro refuerzan la hipótesis de partida de los autores, según la cual el período de los gobiernos progresistas estuvo signado por la reducción de la exclusión social y de la pobreza, cumpliendo con lo adeudado por la agenda neo-liberal, aunque no ha estado marcado por una reducción significativa de las desigualdades. En esta línea, se sostiene que el período histórico que finalizó en 2015 muestra diversas tendencias positivas, como la reducción de la desigualdad por ingresos, a partir de las políticas de transferencia condicionada de ingresos y las pensiones a la vejez, así como por la ampliación de las coberturas en salud, educación y vivienda, lo cual funcionó 
como una relativamente eficaz red de contención y protección para los sectores más vulnerados de la población durante las últimas décadas del siglo XX.

Sin embargo, Benza y Kessler se preguntan qué ha sucedido en este período con la promesa de la reducción de la desigualdad. Respecto de este interrogante, responden tentativamente que si existió una reducción de la exclusión pero no de la desigualdad es porque los gobiernos en general no modificaron las bases estructurales de las desigualdades persistentes. Es decir, que no se desarrollaron plenamente políticas que modificaran de manera profunda o radical las relaciones entre las clases, los sexos y los grupos étnicos. Este problema se revela, asimismo, en que las políticas públicas no han logrado mejorar la situación estructural de algunos grupos particularmente vulnerables y excluidos, como las poblaciones indígenas y afrodescendientes.

\section{Reflexiones finales}

Más allá de las limitaciones que pudiéramos señalar a las políticas del ciclo de gobiernos progresistas, se reconoce que durante este período, y particularmente en la Argentina, se produjeron significativos avances en la proclamación de derechos que antes estaban por fuera de la agenda política. Nos referimos, principalmente, a la incidencia de los movimientos de mujeres, los feminismos y las disidencias, que protagonizaron durante losltimos aos y en la actualidad, la promoción de demandas en torno a los derechos sexuales y (no) reproductivos, como la despenalización del aborto, la lucha contra la violencia de género y el reconocimiento de las identidades no binarias, entre otras. Estas demandas son las que actualmente organizan, al menos en nuestro país, una suerte de "movimiento de masas", con el potencial para desnudar problemas estructurales que exceden los reclamos particulares o sectoriales. El ejemplo ms claro fue la demanda por el derecho al aborto legal, seguro y gratuito, ya que se desenmascaró un conjunto de desigualdades que operan en el sistema de salud, pero también en la aplicación de la educación sexual en las escuelas, las limitaciones y los problemas del sistema de justicia, y particularmente las asimetrías socio-económicas de la población, porque son las mujeres de sectores pobres las que padecen las consecuencias del aborto inseguro y clandestino.

Para finalizar, me gustaría retomar el problema ético-político entre "libertad" y “(des) igualdad”. El libro me motivó a pensar que en el futuro las políticas públicas no solamente deberán estar orientadas a paliar las desigualdades que anidan en los sectores más desfavorecidos de la población, sino que también deberán orientarse al conjunto entero de la sociedad a través de la educación y la cultura, y en el marco de las nuevas tecnologías de la información y la comunicación, para transformar una concepción de libertad individual que durante décadas ha erosionado los compromisos colectivos y con ellos, las grandes utopías socializadoras e igualitaristas. Una transformación profunda de las desigualdades en la región exigirá una transformación profunda en las subjetividades amasadas por el paradigma neoliberal. 